This paper is part of the Proceedings of the $3^{\text {rd }}$ International Conference on Design,

\title{
How urban residents improve their satisfaction with drinking water in the Pacific Northwest, USA
}

\author{
R. L. Mahler ${ }^{1}$ \& M. E. Barber ${ }^{2}$ \\ ${ }^{1}$ Soil Science Division, University of Idaho, USA \\ ${ }^{2}$ Department of Civil and Environmental Engineering, \\ University of Utah, USA
}

\begin{abstract}
Urban residents of the Pacific Northwest region of the USA consider drinking water their most important water resource issue. We surveyed the urban public about their satisfaction with their drinking water in 2002, 2007, 2012 and 2015. Data were collected using statistically designed mail-based surveys. The 2015 survey was designed to probe further into residents' usage of bottled water, in-sink filters and other ways urban consumers improved the quality of their drinking water. Each of the four surveys was sent to more than 2,200 randomly chosen residents of Alaska, Idaho, Oregon and Washington. Return rates in excess of 50\% were received for each survey ensuring that the results are statistically valid. Over $84 \%$ of the urban residents consider their drinking water safe. Despite the high level of satisfaction with the drinking water resource 2015 survey numbers indicated that $18.6,24.7$ and $39.9 \%$ of the survey respondents use water softeners, bottled water and water filters as an add on to their municipally supplied drinking water, respectively. The use of in-house water filters in urban areas has significantly increased with time (25\% in 2002 vs. $40 \%$ in 2015). Public campaigns to discourage the waste associated (plastic and energy) with bottled water are starting to impact homeowner use. Overall, the urban public is satisfied that their home drinking water is safe; however, there is enough skepticism to feed large markets for both filters and bottled water in urban areas of the region. This is in contrast to less urban areas where the use of in-home water filters and bottled water is 44 and $52 \%$ lower, respectively.
\end{abstract}

Keywords: public opinion, drinking water issues, bottled water, water filters, home water treatment. 


\section{Introduction}

For the last 15 years residents of the Pacific Northwest have considered safe drinking water to be the major environmental issue in the region. In general, well over $80 \%$ of residents have been satisfied with the safety and quality of their drinking water. However, this high satisfaction level is on the decline - especially in urban areas. Consequently, this study was designed to determine the steps urban residents are taking to improve their drinking water resource.

\section{Background}

A safe and plentiful drinking water supply is widely considered to be a basic human right. Estimates of the minimum per capita water requirement vary widely [1]. Daily water requirements range from low values of 7 to 50 liters per capita per day $(1 / \mathrm{c} / \mathrm{d})$ to high estimates of between 1,369 and 4,654 1/c/d [1-6]. The $50 \mathrm{l} / \mathrm{c} / \mathrm{d}$ basic water requirement covers the following four basic water needs: (1) drinking water for survival; (2) human hygiene; (3) sanitation services; and (4) household food preparation [2]. From a drinking water stand point the average human should consume between 1.8 and $2.01 / \mathrm{d}[4,5,7]$.

Drinking water has been protected and treated to some extent by societies for over 3,000 years. The ancient Mesopotamians were the first to link certain human activities with water that was unsafe for drinking. They established setback distances between drinking water sources and tanneries, cemeteries and slaughterhouses. Later the Romans learned how to seek the best water sources, transport it to reservoirs using aqueducts, use sand filters to make it purer and then pipe it to fountains in cities where it could be conveniently accessed by the masses. Since the 1880s many cities in Europe and North America have taken on the responsibility of providing safe drinking water for citizens first by filtration and then by chlorination to remove microbial pathogens. By the 1950 s guidelines for inorganic chemicals including nitrate-N and lead were developed in the USA.

The explosion in the development and use of organic chemicals by industry and agriculture led to increased scrutiny and the development of standards by the 1970s. To further protect Americans Congress passed the Safe Drinking Water Act of 1974. Consequently, both human-made and natural radionuclides were evaluated and drinking water standards for these were developed. Finally, the clarity (turbidity) of surface waters used as drinking water was regulated. Today the five categories of water contaminants regulated by the Environmental Protection Agency include: (1) microbial pathogens; (2) inorganic chemicals; (3) organic chemicals; (4) radionuclides; and (5) turbidity.

Since 1987 in the USA an increased emphasis has been placed on public education as a mechanism to improve the nation's water resources through knowledge and voluntary actions. In the four-state (Alaska, Idaho, Oregon, Washington) Pacific Northwest Region, a comprehensive survey instrument was developed to provide base-line information on public attitudes regarding water resources in 2002 from which future outreach (Extension) programming outcomes can be measured $[8,9]$. This initial regional survey documented public attitudes 
about water resources in 2002. At that time, it was anticipated that follow-up water resource surveys would be conducted at 5- (2007), 10- (2012), 15- (2017), 20(2022) and 25- (2027) year intervals. We have now surveyed the urban public about their satisfaction with their drinking water in 2002, 2007, 2012 and 2015. The 2015 survey which is presented in this paper was designed to probe further into residents' usage of drinking water, more specifically bottled water, in-sink filters, water softeners and other ways urban consumers improved the quality of their drinking water. This paper evaluates information about public perceptions, attitudes and consumption of drinking water provided by public water systems in urban areas of the Pacific Northwest. This paper is a summary of our findings.

\section{Methodology}

A survey instrument was developed to access public priorities, attitudes and concerns about water resource issues in the Pacific Northwest. The survey was administered to the general public in 2002, 2007, 2012 and 2015 to evaluate changes over time. The specific responses to questions in the 2002, 2007 and 2012 surveys have previously been analyzed and published [11, 12]. Some of this published data will be used as a comparison to the 2015 data. $50 \%$ of the 2015 survey consisted of questions included in 2002, 2007 and 2012. The other 2015 survey questions were new and were designed to further probe urban drinking water issues that became apparent form earlier surveys.

Nine specific survey questions in the 2015 survey that were evaluated in this paper included:

Is your home drinking water safe?

What are the major contaminants in your drinking water?

Do you use bottled water?

Why do you use bottled water?

What is the major problem associated with the use of bottled water?

Do you use an in-home water filter?

Why do you use an in-home water filter?

Do you use a water softener?

Why do you use a water softener?

As in 2002, 2007 and 2012 a target of 950 completed questionnaires was chosen as the survey goal in 2015 to result in a sampling error of $4-6 \%$ [13]. The survey process was designed to receive a completed survey return rate in excess of $50 \%$. Addresses were obtained from a professional social sciences survey company (SSI, Norwich, CT). Four mailings were planned to achieve the $50 \%$ return rate [14]. The mailing strategy used was identical in in all four survey years [15].

Surveys were actually sent to approximately 2,100 residents in each survey; however, because of address changes, deaths of people on the mailing list and delivery problems, the actual sample population was close to 1,900. Since the survey process was designed to receive a completed survey return rate in excess of $50 \%$, if more than 960 surveys were returned completed, then sampling error could be assumed to be less than $5 \%[13,14]$. 
Answers to the 2015 survey questions were coded and entered into Microsoft Excel. Missing data were excluded from the analysis. Data was evaluated from only the respondents that could be identified as urban. Thus the data from respondents living in rural areas was excluded from analysis. The data were analyzed at two levels using SAS $[15,16]$. The first level of analysis generated frequencies, while the second level evaluated the impacts of demographic factors. Significance $(\mathrm{P}<0.05)$ to demographic factors was tested using a chi-square distribution $[15,16]$.

\section{Results and discussion}

The survey methodology used in this study was not designed to be unique, but rather to follow the methodologies used previously in 2002, 2007 and 2012 so that data could be compared over time. The survey methodology was designed to be used with the best current scientific information to point out the strengths and weaknesses of drinking water delivered by municipalities to urban consumers in the Pacific Northwest. The short term goal was to develop and deliver appropriate education programs for urban drinking water consumers.

The 2015 Pacific Northwest Water Issues Survey achieved a return rate of $52.9 \%$. Over $68 \%$ of survey respondents lived in communities of more than 25,000 people - and were thus considered to be urban residents. $46 \%$ of respondents had lived in the Pacific Northwest (states of Alaska, Idaho, Oregon, Washington) all their lives. $88 \%$ were high school graduates. Overall, the demographics of the survey respondents closely reflected the actual demographics of adults in the region. Consequently, when coupled with the with the low sampling error of the survey, respondents are equated to residents in the following discussion. The results presented focus on the $68 \%$ of the surveyed public living in urban areas of the region.

\subsection{Urban view of drinking water}

Over 92, 90, 86 and 84\% of urban residents in 2002, 2007, 2012 and 2015, respectively, felt that their tap water was safe to drink (Table 1). The long-term trend is that fewer urban residents think their drinking water is safe; however, a vast majority of residents $(84 \%)$ still consider their tap water safe. More urban residents thought that their drinking water was safe in 2007 than in $2015(0.02 *)$.

The demographic factors of gender, age and educational level impacted how urban residents viewed the safety of their water. Based on the 2015 survey males were more likely to consider their tap water safe than females $(94.3$ vs. $75.0 \%)$. Urban residents older than 60 considered their tap water safer than people younger than 50 (88.2 vs. $79.1 \%$ ). Urban residents with some college education were more likely to consider their water safe than high school graduates (92.1 vs. 76.9). Similar demographic trends were observed in earlier surveys $[11,12]$.

One out of four urban residents used bottled water for drinking (Table 1). This percentage is significantly lower than the 2007 survey results. Almost $40 \%$ of 
Table 1: Urban residents' opinion about drinking water safety, use of bottled water and use of in-home water filters in 2002, 2007, 2012 and 2015 based on Pacific Northwest Water Resource Survey.

\begin{tabular}{|c|c|c|c|c|}
\hline Issue & 2002 & 2007 & 2012 & 2015 \\
\hline & \multicolumn{4}{|c|}{ 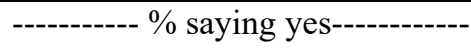 } \\
\hline I believe my tap water is safe to drink & 92 & 90 & 86 & 84 \\
\hline I use bottled water & 28 & 34 & 26 & 25 \\
\hline I use an in-home water filter & 21 & 26 & 34 & 40 \\
\hline
\end{tabular}

urban residents have a supplemental water filter in their home. This percentage has significantly increased since the 2012 survey.

Even though a sizable majority of urban residents consider their drinking water safe, approximately $20 \%$ of survey respondents were able to identify at least one contaminant that may be present in their supplied drinking water (Table 2). Organic chemicals and microbial pathogens were cited by 13 and $12 \%$ of urban residents, respectively, as possibly being present in their water supply. Nitrates and phosphates were cited by $6 \%$ of respondents as possibly being a problem, while all other contaminants listed in the survey form were cited by less than $5 \%$ of the survey takers. The low numbers cited by the public indicate the concern about any of the contaminants often found in drinking water supplies across the USA are relatively low in the Pacific Northwest.

Table 2: Drinking water contaminants that urban residents suspect to be in their drinking water based on 2015 water resources survey.

\begin{tabular}{lc}
\hline Water contaminant & Is a problem in drinking water \\
\hline & $\%$ \\
Organic chemicals & 13 \\
Microbial pathogens & 12 \\
Nitrates & 6 \\
Phosphates & 6 \\
Pesticides & 4 \\
Lead & 3 \\
Radionuclides & 2 \\
Arsenic & 2 \\
Mercury & 1 \\
\end{tabular}

The demographic factors of gender and age had an effect on residents worrying about specific contaminants in drinking water. Residents younger than 40 were more likely to worry about contaminants in their drinking water than people older than 40 (24.2 vs. 9.4\%). Also, females were more likely than males to be worried about specific contaminants in their drinking water (22.6 vs. $13.1 \%)$. 


\subsection{Bottled water}

Almost one out of four urban residents chose to use bottled water for at least a portion of their home water consumption in 2015. This observation was similar in 2012; however, the use of bottled water by urban residents in the Pacific Northwest has significantly declined since 2007 (Table 1).

Two thirds of urban residents that use bottled water claim that it is safer than their tap water source as their primary reason for this action (Table 3). Another $19 \%$ of bottled water users cited this source of drinking water as being more convenient, while another $10 \%$ buy bottled water primarily as a safety back up to their tap water supply. $4 \%$ of bottled water users did not supply a reason for their actions.

Table 3: Major reasons for the use of bottled water in the home by the $24.7 \%$ of urban residents that use bottled water based on 2015 Pacific Northwest Water Resources Survey.

Reason for using bottled water $\quad$ Percentage of bottled water users

Safer than tap water $\quad 67$

More convenient 19

Back up safety 10

No reason provided 4

Based on the analysis of the survey data it is apparent that a majority of urban residents that were worried about a specific contaminant in their tap water, were the ones likely to be using bottled water. Conversely, very few of the urban residents that considered their tap water safe were likely to use bottled water. Annual drinking water quality reports are issued to the public by water providers in all urban areas. These reports verify the actions taken by water systems to ensure that drinking water meets federal standards.

$75 \%$ of urban residents do not use bottled water. The high cost of this product was cited as the primary reason for most residents not using bottled water (Table 4). Another $39.2 \%$ of residents cited the waste of plastics and energy as the primary reason to not use bottled water. Bottled water was not considered as safe as tap water by another $14.3 \%$ of residents. Fewer residents cited the limited shelf life of bottled water and the lack of storage space as the primary reason for not using bottled water. The top three reasons cited for not using bottled water were scientifically sound. Consequently, over $90 \%$ of urban residents that do not use bottled water have valid reasons.

\subsection{In-home water filters}

The percentage of urban residents having a supplemental in-house water filter system increased from $21 \%$ in 2002 to $39.8 \%$ in 2015 (Table 1). Residents justified 
Table 4: Urban residents' view of the major problem associated with the use of bottled water based on 2015 Pacific Northwest Water Issues Survey.

\begin{tabular}{lc}
\hline Major problem with bottled water use & Percentage of all urban residents \\
\hline & \\
High cost of bottled water & 46.4 \\
Waste (plastic etc.) & 32.9 \\
Not as safe as tap water & 14.3 \\
Storage space & 3.9 \\
Limited shelf life & 2.0 \\
No reason given & 0.5 \\
\end{tabular}

this supplemental filter system several ways (Table 5). The most common reason for using a supplemental filter was that it made drinking water taste better (36.9\%). Over 35\% of urban residents justified the in-house filter by indicating that it made their drinking water safer. Another $15.4 \%$ thought that it made their drinking water smell better, while $8.0 \%$ thought that their water appeared clearer. Fewer than $5 \%$ of the residents with filter did not provide a reason for the use of an in-home filter.

Table 5: Major reasons for the use of in-home water filters by the $39.8 \%$ of urban residents that use them based on 2015 Pacific Northwest Water Resources Survey.

Reason for using in-home filter

Percentage of filter users

Makes water taste better

Makes water safer

Makes water smell better

15.4

Makes water clearer

8.0

No reasons given

The $39.8 \%$ of urban residents using a water filter used a variety of devices that could be placed into three categories. These categories included: (1) pour through filters; (2) filters attached to the kitchen sink faucet; and (3) a heavy duty system that could be installed under the kitchen sink or someplace else on the home water intake line. Approximately $40 \%$ of the installed filters were simple pour through filters. Over time the cartridges in these filters wear out and must be replaced. Identified problems with these filters include low drinking water yields and the need to change filter cartridges often (Table 6).

Over $34 \%$ of residents having filters used filters attached to the kitchen sink faucet. Residents liked the quantity of drinking water produced by these filters but had several complaints. The most common complaint was that the filter was often in the way making the kitchen sink area less useable. Residents also complained about the cost and required frequency of changing the filter cartridge (Table 6). 
Table 6: The problems associated with pour through filters, filters attached to sink faucets and heavy duty plumbed filters identified by the $39.6 \%$ of urban residents that have used in-house filters based on 2015 Pacific Northwest Water Issues Survey.

\begin{tabular}{lll}
\hline In-home filter method & Primary problem & Secondary problem \\
\hline Pour through & Low water yield & Change filter often \\
Sink filter & In the way & Change filter often \\
Heavy duty system & Installation cost & High operating cost
\end{tabular}

Approximately $26 \%$ of filter owners had a heavy duty system. These systems were expensive to install and maintain. These included systems with carbon filters, reverse osmosis and distillation units. A major problem with these systems were the installation and operating costs. Despite these problems virtually all owners were very satisfied with the quality of drinking water produced.

\subsection{Water softeners}

Approximately $19 \%$ of urban residents use water softeners in their households. These urban residents believe that the water softening process improves their water for various uses. Over $30 \%$ of water softener users cited improved bathing as the primary reason for using a softener (Table 7). Another $28.6 \%$ of water softener users thought that the device improved the clothe laundering process. They claim that their clothing was cleaner. Almost $17 \%$ felt that the soft water was better for their pipes, while another $13.9 \%$ thought that their water tasted better after being softened. Water safety was not much of an issue as only $6 \%$ of the respondents thought that it made their drinking water safer (Table 7).

Table 7: Major reasons for the use of a water softening system in the home by the $18.6 \%$ of urban residents that use them based on 2015 Pacific Northwest Water Resources Survey.

Reason for using water softener $\quad$ Percentage of softener users

Better for bathing

Better for washing clothes

Better for home pipes

Water tastes better

Makes water safer for drinking

No answer provided
30.4

28.6

16.8

13.9

6.1

4.2

Females were significantly more likely to cite the bathing $\left(0.006^{* *}\right)$, laundering $\left(0.001^{* *}\right)$ and taste benefits $\left(0.03^{*}\right)$ of softened water than males. 
Conversely, males were more likely to say that softened water benefited the household pipe infrastructure. Most survey respondents regardless of gender realized that a water softener did not positively impact drinking water safety. The demographic factors of age and education level did not affect how an urban resident felt about water softeners.

\subsection{Comparison with less urban residents}

Less urban Pacific Northwest residents are defined as people living in communities between 5,000 and 24,999 people. These communities are served by public water suppliers that fall under the same regulations as the larger urban communities. However, the 2015 survey results showed that the less urban Pacific Northwest residents viewed their drinking water resources differently than their more urban counterparts. The less urban residents are not rural. Their drinking water supplier is not any different than a community serving water to 500,000 people.

Less urban residents were more likely to consider their drinking water safe than the group classified as urban residents (Table 8). A higher percentage of less urban residents were satisfied with their drinking water than regular urban residents. People in the less urban category were less likely to use bottled water and in-home water filters to treat drinking water.

Table 8: Compared to drinking water issues in urban areas $(>25,000$ people) of the Pacific Northwest in 2015, residents living in more rural areas (5,000 to 24,999 people) were more likely to.

Issue

Drinking water safety

Drinking water satisfaction

Bottled water

In-home water filter
Rural residents were more likely to....

Consider their drinking water safe

Be more satisfied with drinking water

Not use bottled water

Not use an in-home water filter

Based on the comparisons of the urban and less urban water users an obvious question is: Could the urban population be divided into a regular urban and large urban category? Statistically differences were not found by further division of the urban group. Also, comparison to people in communities of less than 5,000 people does not work because some residents are attached to public water supply systems, while others have their own private well or share a water source with only a few households. These two situations are not regulated by the Safe Drinking Water Act of 1974.

\section{Conclusions and recommendations}

Over $84 \%$ of the urban residents consider their drinking water safe. Despite the high level of satisfaction with the drinking water resource 2015 survey numbers 
indicated that $18.6,24.7$ and $39.9 \%$ of the survey respondents use water softeners, bottled water and water filters as an add on to their municipally supplied drinking water, respectively. The use of in-house water filters in urban areas has significantly increased with time (25\% in 2002 vs. $40 \%$ in 2015$)$. Even though a sizable majority of residents consider their tap water safe most people still consider bottled water to be safer. Public campaigns to discourage the waste associated (plastic and energy) with bottled water are starting to impact homeowner use.

Overall, the urban public is satisfied that their home drinking water is safe; however, there is enough skepticism to feed large markets for both filters and bottled water in urban areas of the region. This is in contrast to less urban areas where the use of in-home water filters and bottled water is 44 and 52\% lower, respectively. Key findings of this study include:

- $\quad$ Pacific Northwest residents are very interested in water resources. This is evident because $52.9 \%$ of residents that received the 2015 survey took the time to fill out and return this survey. Survey responses to most other issues in the region do not get such a high response rate.

- The demographics of the urban residents who completed the survey closely reflected the actual demographics of adults in the region. Thus respondents can be equated to residents in this study.

- $\quad$ The demographic factors of gender, age and educational level impacted how urban residents viewed the safety of their drinking water. Males considered drinking water safer than females and older residents thought that drinking water was safer than younger residents.

- $\quad$ Only $20 \%$ of urban residents were able to identify contaminants that they suspected in their drinking water supply.

- $\quad$ Almost one out of four urban residents chose to use bottled water for at least a portion of their home water consumption in 2015. Two-thirds of urban residents that use bottled water claim that it is safer than their tap water source as their primary reason for this action.

- $\quad 75 \%$ of urban residents do not use bottled water. The high cost of this product and the energy used and waste generated by this use were the major reasons for not using bottled water.

- $\quad$ The percentage of urban residents having a supplemental in-house water filter system increased from $21 \%$ in 2002 to $39.8 \%$ in 2015 . Residents justified this supplemental filter system the following ways: (1) it made drinking water taste better $(36.9 \%)$; (2) it made their drinking water safer (35.2\%); (3) it made their drinking water smell better (15.4\%); and (4) it made their water appear clearer $(8 \%)$.

- Approximately $19 \%$ of urban residents use water softeners in their households. Residents justified the water softener system the following ways: (1) improved bathing (30\%); (2) improved the clothe laundering process $(28.6 \%)$; (3) better for household pipe system $(17 \%)$; and (4) improved water taste $(13.9 \%)$.

- $\quad$ Compared to people living in cities with more than 25,000 people less urban Pacific Northwest residents viewed their drinking water resources 
differently than their more urban counterparts.

- $\quad$ Less urban residents were more likely to consider their drinking water safe than urban residents. A higher percentage of less urban residents were satisfied with their drinking water than regular urban residents. People in the less urban category were less likely to use bottled water and in-home water filters to treat drinking water.

This study was important because it showed scientists how urban Pacific Northwest residents are individually enhancing their already safe drinking water resources. The information collected from this study will be used to develop proactive educational programs for adults in the region.

\section{References}

[1] Chenoweth, J.L. Minimum water required for social and economic development. Desalination, 229:245-256, 2008.

[2] Gleick, P.H. Basic water requirements for human activities: meeting basic needs. Water International, 21(2):83-92, 1996.

[3] Falkenmark, M. Fresh water - time for a modified approach. Ambio, 15:192200, 1986.

[4] World Water Assessment Programme. Water for people, water for life: The United Nations World Water Development Report, UNESCO Publishing/ Berghahn Books, Paris, 2003.

[5] WHO/UNICEF. Joint monitoring programme for water supply and sanitation, Global Water Supply and Sanitation Assessment 2000 Report, WHO/UNICEF, Washington, 2000.

[6] Howard, G. \& Bartram, J. Domestic water quantity, service, level and health, World Health Organization, Geneva, 2003.

[7] Greenhalgh, A. Healthy living - water, BBC Health, March, 2001.

[8] Mahler, R. L., Simmons, R., Sorensen, F. \& Miner, J.R. Priority water issues in the Pacific Northwest, Journal of Extension, [On-line], 42(5). Article 5RIB3. Available at: www.joe.org/joe/2004october/rb3.php, 2004.

[9] Mahler, Robert L., Smolen, M.D., Borisova, T., Boellstorff, D.E., Adams, D.C. \& Sochacka, N.W. The national water survey needs assessment program. Natural Sciences Education, 42(1):98-103, 2013.

[10] Mahler, R.L., Gamroth, M., Pearson, P., Sorenson, F., Barber, M.E. \& Simmons, R. Information sources, learning opportunities and priority water issues in the Pacific Northwest, Journal of Extension [On-line], 48(2). Article 2RIB2. Available at: www.joe.org/joe/2010april/rb2.php, 2010.

[11] Dunlap, R.E. Trends in public opinion toward environmental issues: 19651990. Society \& Natural Resources, 4:285-312, 1991.

[12] Mahler, R.L., Simmons, R. \& Sorensen, F. Drinking water issues in the Pacific Northwest. Journal of Extension, [On-line], 43(6). Article 6RIB6. Available at: www.joe.org/joe/2005december/rb6.php 2005.

[13] Salent, P. \& Dillman, D. How to Conduct Your Own Survey. John Wiley and Sons, New York, 1994. 
[14] Dillman, D. Mail and Internet Surveys: The Tailored Design Method. John Wiley and Sons, New York, 2000.

[15] SAS Institute Inc. SAS Online Document 9.1.3. Cary, North Carolina: SAS Institute Inc., 2004.

[16] Babbie, E. The practice of social research. 3rd edition. Wadsworth Publishing Company. Belmont, CA. pp. 359, 424, 1983. 